\title{
Excess mortality from mental, neurological and substance use disorders in the Global Burden of Disease Study 2010 - CORRIGENDUM
}

\author{
F. J. Charlson, A. J. Baxter, T. Dua, L. Degenhardt, H. A. Whiteford and T. Vos
}

doi: http://dx.doi.org/10.1017/S2045796014000687, Published online: 15 December 2014

A number of minor errors and omissions occurred in the above mentioned article [1], which are given below.

The following text ought to have appeared in the results section of the abstract:

The 13 million excess deaths reported should be treated with caution as the sum of excess deaths of individual disorders are not additive or control for comorbidity between mental and substance use disorders.

Page 127, line 14, where it reads "There were no deaths causally attributed to intellectual disability; however, excess deaths in people with idiopathic intellectual disability were estimated to be substantial at over 900000 deaths globally in 2010." the author wishes to add the following comment:

This estimate of excess deaths relates to ALL underlying causes of intellectual disability, not just those from idiopathic origin.

Page 127, line 5 of the Substance use disorders section, '5 million' should be revised to '1.95 million'.

Page 127, fig. 4, the top left graph should be as is displayed in the re-numbered fig. 4.a below:
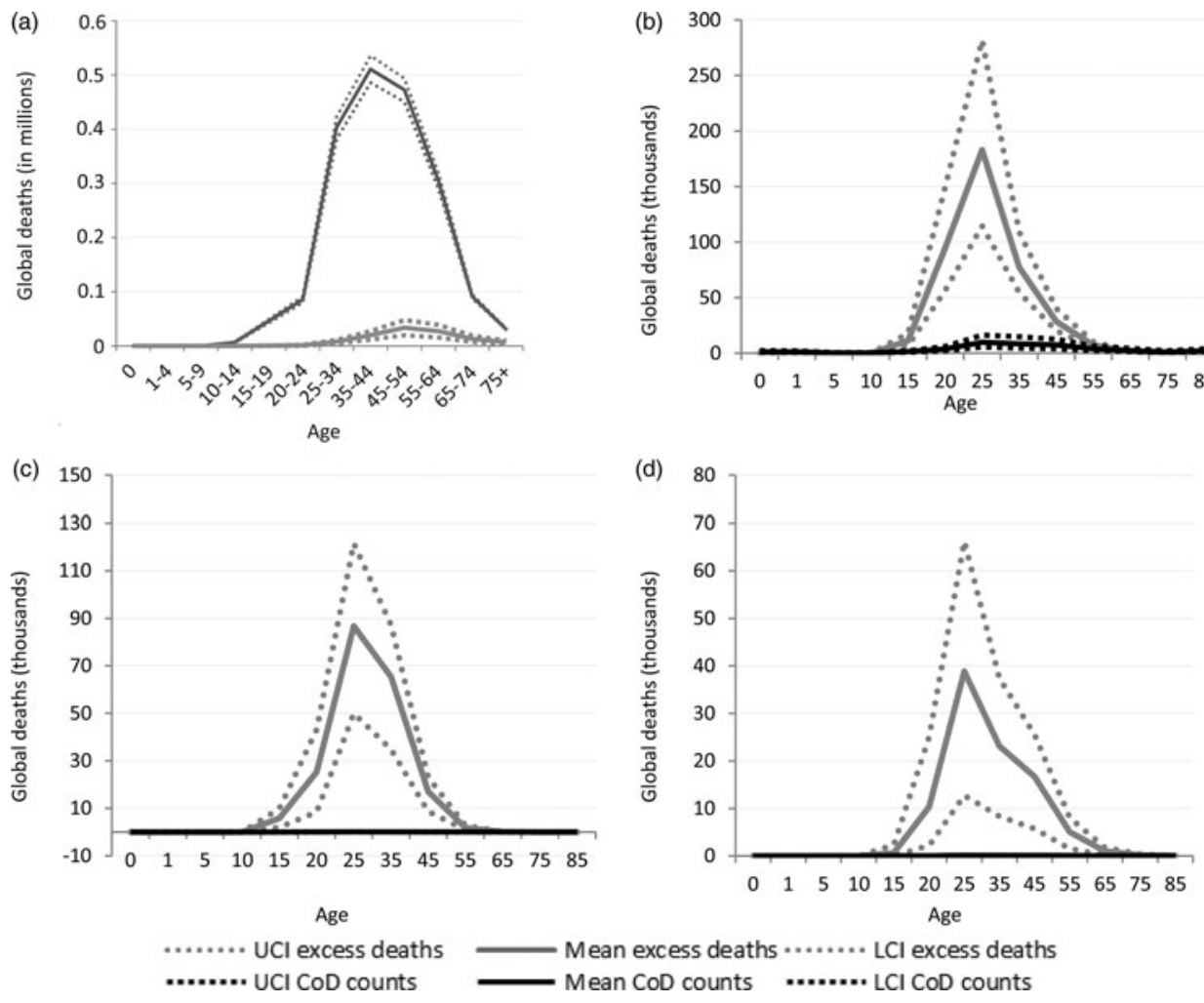
Page 127, the captions for fig. 4 should read as follows:

Fig. 4.a. Numbers of Cause-Specific and Excess Deaths Attributed to Alcohol Use Disorders, by Age, with Uncertainty, 2010.

Fig. 4.b. Numbers of cause-specific and excess deaths attributed to Opioid Dependence in 2010, by age and with upper and lower 95\% CI.

Fig. 4.c. Numbers of cause-specific and excess deaths attributed to Amphetamine Dependence in 2010, by age and with upper and lower $95 \%$ CI.

Fig. 4.d. Numbers of cause-specific and excess deaths attributed to Cocaine Dependence in 2010, by age and with upper and lower $95 \% \mathrm{CI}$.

*Note: Cannabis not shown as there was no cause-specific or excess mortality.

\section{Reference}

Charlson FJ, Baxter AJ, Dua T, Degenhardt L, Whiteford HA, and Vos T (2015). Excess mortality from mental, neurological and substance use disorders in the Global Burden of Disease Study 2010. Epidemiology and Psychiatric Sciences 24, pp 121-140. doi:10.1017/S2045796014000687. 